\title{
POST-KOBE APPROACH FOR DESIGN AND CONSTRUCTION OF BASE-ISOLATED BUILDNGS
}

\author{
Masayoshi NAKASHIMA ${ }^{1}$, Peng PAN ${ }^{1}$, Dan ZAMFIRESCU ${ }^{2}$, and Ruediger WEITZMANN ${ }^{1}$ \\ ${ }^{1}$ Disaster Prevention Research Institute, Kyoto University, \\ Gokasho, Uji, Kyoto Japan, nakashima@archi.kyoto-u.ac.jp \\ ${ }^{2}$ Technical University of Civil Engineering Bucharest, \\ Bucharest 72302, Romania
}

\begin{abstract}
Japan has two decades of experience in designing and constructing baseisolated building structures. Construction has increased significantly since the 1995 Hyogoken-Nanbu (Kobe) earthquake, having reached over 150 annual construction projects. Many new developments and refinements have been made in the material, device, design, and construction of these structures. This paper summarizes recent design and construction of base-isolated building structures in Japan, including statistical data with respect to the common usage as well as the number of new projects.
\end{abstract}

Key Words: base-isolation, buildings, bearings, dampers, seismic design, peer-review

\section{INTRODUCTION}

The concept of modern seismic base-isolation emerged in the early 1970s in New Zealand (Skinner et al 1993). As in other earthquake-prone developed countries, the application of base-isolation in Japan began in the early 1980s (the first building was finished in 1983). The start was slow and until 1985 only three demonstration projects were completed. During the 1985-1994 period, during the Japanese economic boom, the number of base-isolated buildings began to increase, reaching about ten buildings per year (Fig.1), and Japan became a leading country in the number of base-isolated buildings. Design was characterized by a very large scatter in the main design parameters and in the choice of isolation devices.

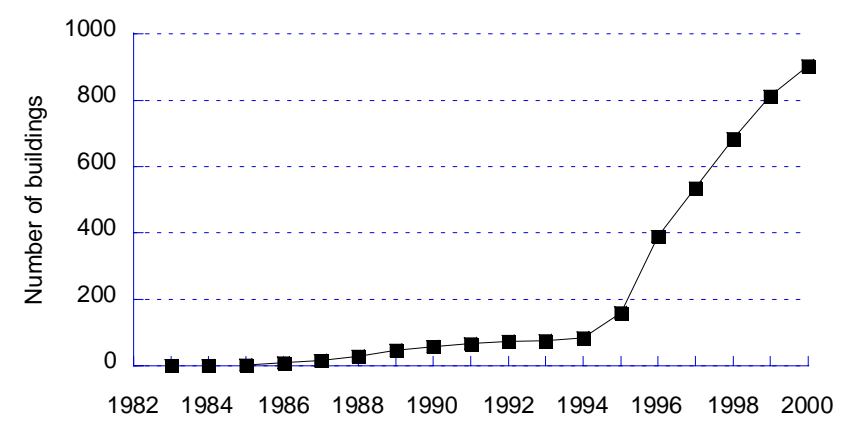

Fig. 1 Isolated buildings until 2001 (Building 1990-2002; Report 2002)

After the 1995 Kobe earthquake a new era began for seismically isolated buildings in Japan 
(Fig.1) (Building 1990-2002; Report 2002). The number of base-isolated buildings significantly increased to more than 150 buildings per year. Seismic isolation moved from the experimental stage to the mass production stage, characterized by relatively standard detailing and devices. Clark et al. (2000) reasoned that the explosion of base-isolation applications was caused by the devastating human and economic losses that led a search for alternatives to traditional seismic design approaches. The observed damage to buildings also produced a sense of doubt regarding the reliability of traditional construction approaches particularly concerning damage protection of the structure and its contents. This paper reviews the state-of-the-practice of Japanese design and construction of seismically isolated buildings to share with the readers the experience and knowledge accumulated in this field over the last 20 years.

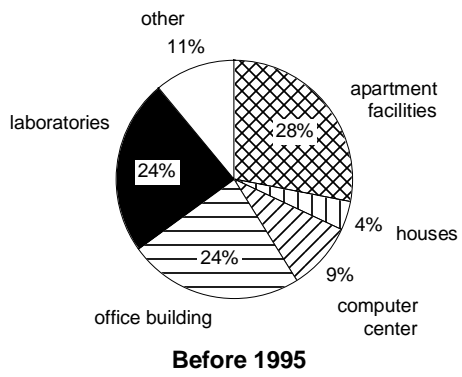

(a)

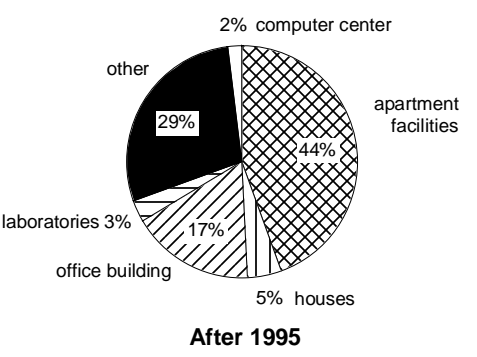

(b)

Fig. 2 Types of facilities (Report 2002)

\section{CONSTRUCTION STATISTICS}

The built floor area, an important index of the development in practical application, recorded a leap after 1995 and continued to increase slowly in more recent years. The main reason is the increase in the building height; the average number of stories rose from four to five stories before 1995 to about eight stories after. Before 1995, many base-isolated buildings were relatively small buildings including laboratories, experimental offices, and dormitories built and owned for demonstration purposes by construction companies. Funding for these buildings typically came from construction companies' research investments, and the buildings used many different types of proprietary isolation systems. After 1995, types of facilities such as apartments, office buildings, hospitals, and government buildings increased to a very consistent proportion (higher than 90\%).

Taking advantage of the development in design and practical application of new base-isolated buildings, rehabilitation of existing buildings using base-isolation became more wide-spread in recent years. Rehabilitation solutions for existing buildings were about $10 \%$ of the total seismically isolated designs approved in recent years (Building 1990-2002).

The most common types of used isolators in recent years are NRB (Natural Rubber Bearings), HDRB (High Damped Rubber Bearings), LRB (Lead Rubber Bearings) and Sliding Bearings (SB). In about half of the buildings only one type of isolator is used, and a combination of popular types or a combination with sliding bearings (SB) was chosen for the remaining structures. In the earliest years (before 1994), NRB were used in more than 65\% of cases (Miyazaki 1985). Between 1996 and 1998 the proportion of HDRB and LRB increased to levels of usage relatively equal with NRB. The recent trend is a significant reduction in use of the HDRB solution. NRB and LRB are used in the majority of the recent designs, and adoption of SB increases notably. The improved performance of the isolators also explains the increase over time of the mean compressive stress in the isolators.

Prior to 1995, the energy dissipation was usually provided by only one type of damper. In more recent designs, combinations of different types of dampers are more frequent. Steel dampers used in conjunction with lead dampers have proved to be one of the most common combinations. High initial stiffness (to resist wind loads) and good performance to resist a large number of cycles without damage are the main advantages of the lead dampers. Using the lead dampers in conjunction with steel 
dampers, which possess a relatively large yield force, overcomes the disadvantage of the lead dampers (low yield force - reduced energy dissipation). Oil dampers are sometimes used for large structures in order to provide large additional viscous damping.

Variation over time of the design base shear coefficient of the superstructure confirms the advances in design and the better understanding of the behavior of seismically isolated structures. Design practice for base-isolated buildings in Japan commonly involves verification of maximum floor accelerations of the superstructure in order to prevent extended damage to building contents. Although not explicitly prescribed by codes, a general rule is to limit the maximum horizontal acceleration to $3.0 \mathrm{~m} / \mathrm{s}^{2}$. The limit value is based on experimental studies conducted for medical facilities, electronic facilities, and others.

\section{SEISMIC BASE-ISOLATION DEVICES}

\section{Isolators}

The most popular isolators in Japan are natural rubber bearings (NRB) and lead rubber bearings (LRB), followed by high-damping rubber bearings (HDBR) and sliding bearings (SB). Japanese NRB consists of layers of natural rubber with thickness in the range of 3 to $9 \mathrm{~mm}$, intercalated with stiff thin steel plates of 2.5 to $4.5 \mathrm{~mm}$. The manufacturers usually offer a few types of bearings in terms of the rubber's shear modulus; that is, $0.35,0.4,0.45$ or $0.55 \mathrm{~N} / \mathrm{mm}^{2}$. The diameter varies from 500 to 1550 $\mathrm{mm}$, with common values between 600 to $1200 \mathrm{~mm}$. The design maximum deformation is set to about 250 to $300 \%$ in shear strain.

The general layout of HDRB is similar to NRB with the difference that instead of natural rubber, special synthetic rubber that can dissipate energy through loop cycles is used. The $S_{1}$ shape factors (25 to 35 ) are generally smaller with respect to NRB, and the $S_{2}$ factors have a larger variation (3 to 10). The resulting equivalent damping ratio for HDBR is around $20 \%$ for shear strains up to $300 \%$. The maximum design and ultimate deformation values being similar to the NRB.

LRB is a NRB with a lead plug inserted in order to dissipate hysteretic energy. The limits for the maximum compressive stress and the vertical and post-yield lateral stiffness values are similar to the corresponding NRB. The yield force depends on the diameter of the lead plug and is around $100 \mathrm{kN}$ for the $100 \mathrm{~mm}$ lead plug diameter. LRB has a high initial stiffness (about ten to 16 times the postyield stiffness) for relatively low horizontal forces normally produced by wind.
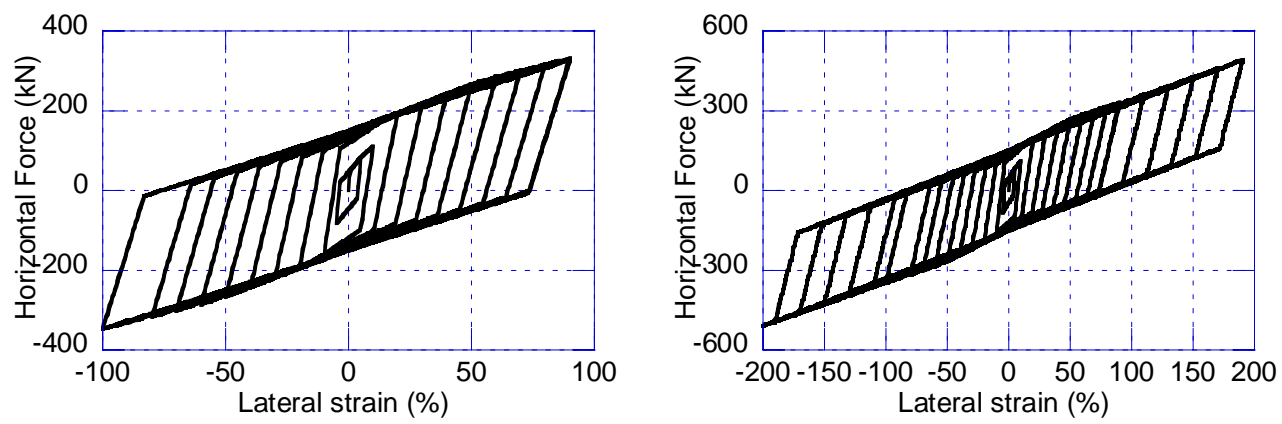

Fig. 3 Example hysteresis loops using the modified bilinear model

The modified bilinear model (Miyazaki 1985) is widely used in Japanese design to represent the nonlinearity and strain-dependent behavior of the horizontal hysterestic behavior of HDRB and LRB. The difference with respect to the common bilinear model is that the main parameters are not constant, but depend primarily on the maximum shear strain experienced in the loading history. Figure 3 shows example hysteresis loops of the modified bilinear model, showing significant changes in both the initial and second stiffness values according to the shear strain. The HDRB constitutive law is similar but depends somewhat more significantly on the maximum shear strain.

The weight of the structure may be supported on bearings consisting of blocks of PTFE 
(polytetrafluorothylene) sliding on plane horizontal stainless-steel plates [Fig.4]. The main characteristic of SB is the high initial lateral stiffness that decreases significantly once sliding is initiated. In order to reduce the very high initial lateral stiffness that may promote higher mode vibrations, SB is sometimes mounted on top of a rubber bearing. The restoring force provided by SB is negligible once the sliding is initiated and consequently the SB's are used in conjunction with other types of isolators (NRB, HDRB, LRB) that possess significant restoring forces.
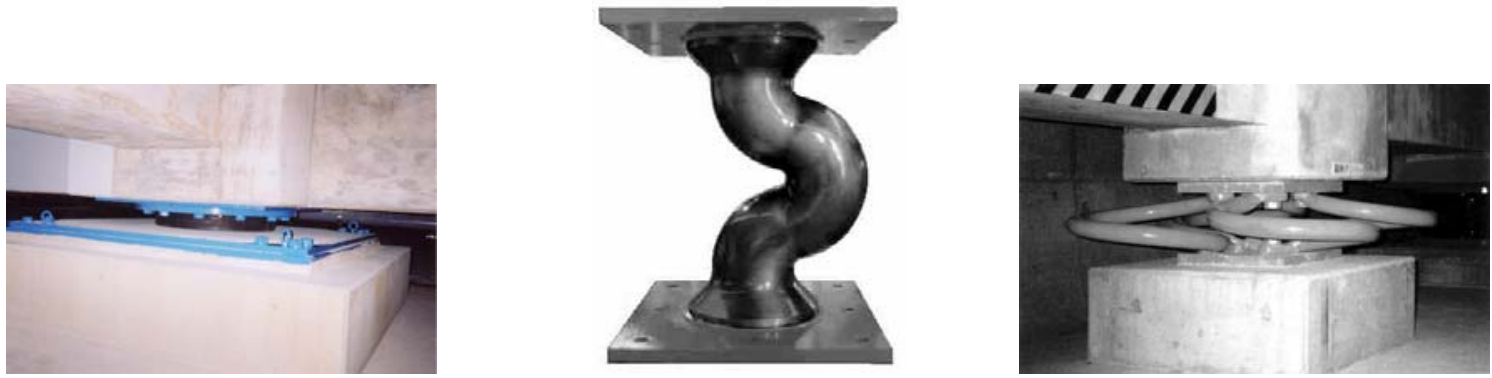

Fig. 4 Seismic isolation devices in Japan: Sliding bearing; Lead damper; Steel coiled damper.

\section{Dampers}

In order to reduce the relative displacement demand on the isolation layer and to stop the horizontal motion as soon as possible after the primary motion, dampers are added to the isolation layer. The lead dampers commonly used in Japan consist of a twisting pure-lead stick curved in a U shape connected at the top and bottom by rigid stiff flanges [Fig.4]. Fatigue curves are provided by manufacturers, and one major advantage of the lead damper is that numerous cycles of large deformations can be sustained without any significant degradation. The lead dampers are commonly used in conjunction with steel coiled hysteretic or oil viscous dampers.

The most popular type of steel damper in Japan dissipates energy through plastic deformation of coiled steel rods [Fig.7]. The coiled solution is adopted primarily to ensure a large yield displacement and large plastic deformation capacity.

Two types of oil (hydraulic) dampers, one with sealing of the damping forces and the other without, are used in Japan. Oil dampers with sealing provide a velocity proportional damping force up to a specified velocity and then a constant damping force beyond the velocity whereas those without sealing supply a velocity proportional damping force for all allowable deformations. As for the mechanism of sealing, mechanical systems (fuses) are commonly adopted. Compared to other types of dampers cited above, the damping forces provided by oil dampers are relatively high. The oil dampers are effective for deformations only in one axis but relatively large space is needed to accommodate oil dampers in the base-isolation layer. Because of these reasons, oil dampers are typically preferred for large-scale structures.

For practical applications, all devices must be submitted for accreditation by the manufacturers to the same committee that approves the seismic base-isolation designs. The accreditation is granted based on the standard test results of a specified number of devices. The accredited devices are specified in catalogs published by the manufacturers.

\section{DESIGN PRACTICE}

For seismic base-isolated structures, the common design practice implies enhanced performance requirements with respect to the general design of structures in Japan (Recommendation 2001):

- $\quad$ L-1 - The building should be fully functional at the occurrence of a significant accidental event.

- $\quad$ L-2 - The associated hazard level is a rare major earthquake, restricted to accidental initiation of yielding of the structural elements.

- $\quad$ L-3 ( $\mathbf{L - 2 + )}$ - Additional performance level is recommended to check the safety margin against the maximum credible earthquake. 
The common practice is to associate a PGV (peak ground velocity) value of $0.25 \mathrm{~m} / \mathrm{s}$ and $0.5 \mathrm{~m} / \mathrm{s}$ for L-1 and L-2 level ground motions, respectively.

Japanese design practice for seismically isolated buildings involves time-history analysis, meaning that acceleration time histories have to be specified. Two groups of accelerograms are commonly adopted. The first group consists of three standard accelerograms: El Centro 1940, Taft 1952 and Hachinohe 1968. The Hachinohe ground motion is preferred mainly due to the long period components. The second group must consider the characteristics of the local site. At least three accelerograms have to be developed in this group. Natural accelerograms recorded in the vicinity of the building site may be used if available. Alternatively, synthetic accelerograms can be constructed. Simplified models for time-history analysis, such as the lumped mass model (stick model) are accepted and commonly used in the design process of base-isolated structures. The analysis models of the isolation layer depend on the types of seismic isolators and dampers. The common models are elastic springs for NRB, bilinear hysteretic for lead and steel dampers, modified bilinear for HDRB or LRB, and viscous springs for oil dampers.

To achieve an effective reduction of the earthquake demands, the ratio of the fixed-base period to the base-isolated period of the structure is recommended to be greater than three. The natural period in the large displacement domain computed based on the isolators tangential stiffness is commonly greater than $3.5 \mathrm{~s}$. The most important response parameters are as follows.

- Maximum displacement of the isolation layer

- Maximum force and displacement of the superstructure

Lately, use of sliding bearings becomes more common to further increase the natural periods of the base-isolated structures. When combined with slide bearings, target natural periods (in the large deformation domain) are between 4 and 5 seconds. Sliding bearings are commonly combined with rubber bearings (which supply horizontal restoring forces).

Seismically isolated buildings in Japan require special licenses from the Ministry of Land, Infrastructure and Transport. The Building Center of Japan (BCJ) and a few other organizations conduct "third-party review" and administer the building approvals for special types of structures.

\section{SPECIAL DESIGN CONSIDERATIONS}

While horizontal vibrations are greatly reduced thanks to base-isolation, vertical vibrations may remain the same compared to those experiences by conventional structures, because of the high vertical stiffness of the base-isolation layer. This increases the importance of vertical motions in the design. The vertical ground motions can impose large vertical accelerations that affect the functionality of the base-isolated buildings. Additionally, the combined vertical and overturning action may induce tensile forces in the isolators. To check the effects of vertical motions, time-history analyses of the designed structure subjected to vertical motions are sometimes carried out.

Seismic base-isolation solutions become less effective for high-rise buildings having longer natural periods. A minor advantage achieved by base-isolation of a high-rise building is a possible reduction of story drifts due to the change of the first mode shape of the isolated structure with respect to the fixed-base equivalent. A more important effect can be expected from the energy dissipation provided by the dampers installed in the isolation layer. For high-rise structures a more efficient solution may be achieved by incorporating the damping devices within the structure instead of baseisolation; nevertheless, application of base-isolation to high-rise buildings increases notably in recent years.

There is a concern regarding the performance of seismically isolated buildings subjected to nearfault ground motions that are characterized by few large high-velocity pulses. The isolated structures are more vulnerable to this type of ground motion. The displacement demanded of the base-isolation layer in such extreme actions may surpass the provided isolation clearance (commonly about $0.5 \mathrm{~m}$ ), and collision would occur between the structure and perimeter retaining walls. Most design did not explicitly consider such behavior. One solution to avoid collision is to place a very strong vertical load truss system in the first story above the isolation level in order to minimize the support points 
(Miyazaki 1997). The idea is to allow the use of large diameter (1300 to $1500 \mathrm{~mm}$ ) isolators that can sustain large compressive forces and lateral deformations of more than $800 \mathrm{~mm}$, also achieving large isolated periods. This solution was adopted in a few projects.

Most of the base-isolated structures constructed before the 1995 Kobe earthquake were instrumented, but the number of the constructed base-isolated structures was limited as shown by Fig.1. After Kobe, the number of base-isolated structures increased significantly, but instrumentation became uncommon. No exact statistics are available about the number and location of base-isolated building structures in Japan, but an estimate is in a range of 100. A number of technical papers are available as for details of real design projects on Japanese base-isolated building structures. For reference, the following two proceedings contain multiple papers that introduce actual design and construction projects implemented in Japan and are written in English: (1) Proceedings of Structural Engineering World Congress 1998, held in San Francisco, U.S. A. and (2) Proceedings of Structural Engineering World Congress 2002, Yokohama, Japan.

\section{CONCLUSIONS AND ACKNOLEDGEMENT}

Statistical data regarding base-isolated buildings notably show that base isolation in Japan has grown remarkable since the 1995 Kobe earthquake, with more than 150 new projects annually. The floor area, height and natural period of base-isolated building structures keep increasing, and the maximum shear exerted into the superstructure remaining low, which is a clear indication of the confidence and maturity of seismic isolation design in Japan. Several issues pertinent to base-isolation are discussed: variation of base-isolation material properties, applications to high-rise buildings, effects of vertical ground motions, and response when subjected to near-fault ground motions. Among these, vertical motion effects (in terms of the assurance of functionality) and possible damage (including collision with the surrounding retaining walls) induced by near-fault motions are identified as issues that have not been fully resolved.

The writers wish to thank Y. Nakata of Nippon Steel Co. and M. Miyazaki of Dynamic Design Co. for providing the writers with photos shown in Figs.4 of this paper. The writers are also grateful to the following individuals for their useful comments on the content of the paper: M. Miyazaki of Dynamic Design Co., H. Kitamura of Tokyo Science University, H. Hayamizu of the Building Center of Japan, and M. Higashino of Takenaka Co. Any errors in this paper are those of the writers alone.

\section{REFERENCES}

Skinner, R. I., Robinson, W. H., and McVerry, G. H. (1993). An Introduction to Seismic Isolation, Wiley, England.

The Building Letter (1990-2002). Building Center of Japan, Tokyo, (in Japanese).

Report on new building technologies - approvals, appraisals and certification (2002). Technical Report of the Building Center of Japan, Building Center of Japan, (in Japanese).

Clark, P. W, Aiken, I. D, Nakashima, M., Miyazaki, M., and Midorikawa, M. (2000). “The 1995 Kobe (Hyogo-ken Nanbu) Earthquake as a trigger for implementing new seismic design technologies in Japan. Lessons Learned Over Time.” Learning From Earthquake Series, Earthquake Engineering Research Institute, Vol.3, 79-109.

Miyazaki M. (1985). "Sumitomo LRB construction method,” Technical Report of the Building Center of Japan, Building Center of Japan, 75-82 (in Japanese).

Recommendation for the Design of Base Isolated Structures (2001). Architectural Institute of Japan, (in Japanese).

Miyazaki M. (1997). "Current of isolated buildings in Japan after 1995 Kobe earthquake," Proccedings of International Post-SMiRT Conference Seminar on Seismic Isolation, Passive Energy Dissipation and Active Control of Seismic Vibration of Structures, Taormina, Italy. 